\title{
TOXICITY DETERMINATION OF CINNAMON OIL-INFUSED ALOE VERA EDIBLE COATING MATRIX ON NORMAL HUMAN LUNG FIBROBLAST MRC-5 CELLS
}

\author{
RAZIFAH MOHD RAZALI ${ }^{1 *}$, NURUL HUDA ABDUL KADIR ${ }^{1,4}$, MAZIAH MOHD GHAZALY ${ }^{1,3}$, \\ KEISHENI GANESON ${ }^{1}$, RASEETHA VANI SIVA MANIKAM ${ }^{2}$ and \\ NURFARHAH HASANAH JAMALUDIN ${ }^{1}$ \\ ${ }^{I}$ Faculty of Science and Marine Environment, Universiti Malaysia Terengganu, \\ 21030 Kuala Nerus, Terengganu, Malaysia \\ ${ }^{2}$ Faculty of Applied Sciences, Universiti Teknologi MARA, Malaysia \\ ${ }^{3}$ Faculty of Medicine, Imperial College London, SW3 6LY, London, United Kingdom \\ ${ }^{4}$ Institute of Tropical Aquaculture, Universiti Malaysia Terengganu, 21030 Kuala Nerus, \\ Terengganu, Malaysia \\ *E-mail:razifah@umt.edu.my
}

Accepted 19 October 2020, Published online 25 December 2020

Fresh produce with all the valuable micro and macro-nutrients preserved are highly demanding for the consumers and extremely profitable in the agriculture sector. However, during the postharvest handling, it involves in various stages immediately following harvest including sorting, cleaning, packaging and cooling before transportation which may require a time to get delivered to various destinations. While these processes take place, various possibilities can affect the quality of the freshness of the product such as pest invasion, changes in the mechanical structure of crops and foreign contaminants. These factors may decrease the freshness and quality of various products at the same time leading to enhancement of crop deterioration.

Despite various risk factors, it could affect greatly on agriculturalist due to risk factors-induced crop deterioration process before it could arrive at its destination for the consumers. However, there have been several methods to overcome the problems such as the use of refrigerated chillers, controlled atmosphere storage, sterilization by both UV and gamma radiation, as well as more commonly, the overutilization of single-use synthetic plastic and wax materials which are a major concern worldwide (Pavlath \& Orts, 2009). Moreover, these preservation methods have a high tendency to give adverse effects to consumers. For instances, the single-use plastics are known to be harmful and toxic to human and animal health chronically. A study by Verma et

* To whom correspondence should be addressed. al. (2016) stated that chemicals within plastics such as bisphenol A, phthalates and flame retardants can affect the endocrine system, which may contribute to cancer and reproductive problems.

Thus, there is an urgent need to create and produce an edible coating matrix as a substitute for the current harmful synthetic substances on the market. The new formulation of edible coating is aimed at the usage of natural materials originated from edible fruits and vegetables to overcome the overutilization of toxic single-use synthetic plastic and wax materials that could be detrimental to human health. This new formulation of the edible coating is aimed to produce a new natural edible coating that is safe, edible and reduce degradation of nutrients in the fruits, as well as at the same time increase e.g. agriculturalist revenue. Edible and biodegradable coating films are not a new idea to this field, however, there are no innovative replacement products from a stable, safe, natural and biodegradable substance to replace the various single-use plastics and wax products in the industry. Furthermore, researchers are highly interested in looking at biodegradable materials to overcome various problems arise from toxic plastic materials. Edible coating films are believed to be one of the most effective ways to maintain the quality and safety of fresh produce due to its potential in extending the postharvest lifespan (Park, 1999; Pavlath \& Orts, 2009). A previous study from Rahman et al. (2017) reported that polymer extracts of Aloe vera have high potential as biomaterials in tissue engineering for its various benefits, including biodegradability, oxygen permeability, antioxidant 
action, cell proliferation and regeneration as well as low toxicity effect. Consequently, Aloe vera could be the best material for film production due to its various biomedical activities such as antitumor, antioxidant, anti-inflammatory, antimutagenic, enhance wound healing and immunomodulatory processes as well as induce antifungal activity (Joseph \& Raj, 2010).

Besides, essential oils (EOs) possess antimicrobial and antioxidant properties and most of them are classified as Generally Recognized as Safe (GRAS) (Atarés \& Chiralt, 2016). Among them, cinnamon oil is well known for its antimicrobial and antioxidative activity which makes it an interesting additive and preservative in food industry especially since they have been used as a natural remedy from ancient times (Noshirvani et al., 2017). Research by Yun et al. (2018) reported that cinnamon extract caused no death in animal following administration at a certain range of concentrations. This has shown that cinnamon is safe to be consumed. However, there is no edible film has been formulated from a combination of Aloe vera and cinnamon, as the main ingredients of the edible coating. On the other hand, it is believed that this combination would be beneficial to protect and preserve fruits and vegetables against insects, as well as prolong its shelf lives.

In this study, we have formulated a new type of edible coating matrix that may replace the toxic single-use synthetic plastic and wax materials, using a combination of stable and natural ingredients consist of Aloe vera and cinnamon oil which are well known for its therapeutic value. Therefore, the current study focuses on formulating of various constituents of cinnamon oil infused into the Aloe vera based to form an edible matrix. Besides, the formulation of the edible coating was tested its cellular cytotoxicity on normal human lung fibroblast MRC-5 cells (as a model), to ensure the safety of the product to be consumed by the consumers. Also, Tween-80 (polysorbate 80, polyoxyethylene sorbitan monooleate) is a nonionic surfactant that is widely used as an emulsifier in cosmetics, pharmaceuticals and food products. US
Food and Drug Administration has approved usage of Tween-80 as an emulsifier (up to 1\%) in foods (Chassaing et al., 2015).

To formulate the new natural edible coating, $200 \mathrm{~mL}$ of distilled water was poured into four beakers following a $4 \mathrm{~mL}$ of glycerol was added to form a mixture. The solutions were homogenised using a food processor. Next, $1 \mathrm{~g}$ of gelatine was added into each beaker. The solutions were then heated at $65^{\circ} \mathrm{C}$ and stirred at $250 \mathrm{rpm}$ on a hot plate magnetic stirrer to form a glycerol-gelatine solution. Aloe vera gel (matrix base) was extracted from its outer cortex using a blade and $10 \mathrm{~mL}$ of the gel was homogenised before undergoing the filtering process. Subsequently, $2.5 \mathrm{~mL}$ of the filtered gel was transferred into the glycerol-gelatine solution made earlier to form the Aloe vera mixture (Razifah et al., 2017). Next, the Aloe vera mixture was prepared in three groups with different ratios of cinnamon oil infused with Tween-80, which were $50: 50,60: 40$, and 70:30 while the matrix with no cinnamon oil and Tween- 80 acted as a control. The solutions were then homogenised and filtered before they were transferred into four different Petri dishes and stored in a desiccator for further experiments. Table 1 shows the exact ratio of the mixture of cinnamon oil, Tween-80 mixture and Aloe-vera, to make up to a total volume of $0.2 \mathrm{~mL}$ gel.

Then, the formulated natural edible coating was tested for its safety using AlamarBlue ${ }^{\circledR}$ cell viability assay to evaluate its cytotoxicity effect on normal human lung fibroblast (MRC-5) cells given. The MRC-5 cells were cultured in RPMI-1640 medium supplemented with FBS $(10 \% \mathrm{v} / \mathrm{v})$, L-glutamine (2 $\mathrm{mM})$, streptomycin $(100 \mu \mathrm{g} / \mathrm{mL})$, and penicillin (50 IU $/ \mathrm{mL}$ ) until reaching $95 \%$ confluence maintained at $37^{\circ} \mathrm{C}$ in a $5 \% \mathrm{CO}_{2}$ humidified environment. Cells were then detached and counted. Cell pellets were used for further experiments (Mazumder et al., 2016). Next, a total of 10,000 human fibroblast MRC-5 cells were seeded into 4 sets of 96-wells plates and incubated for three-time points; 24, 48 and 72 hours, to allow the cells to reach confluency of $85 \%$ in a monolayer (Grigoryev, 2014).

Table 1. The exact volume ratios of cinnamon oil and Tween-80 consist in the Aloe vera based

\begin{tabular}{ll}
\hline Volume ratio & Description \\
\hline Control & No cinnamon oil and Tween-80 added \\
$50: 50$ & $0.1 \mathrm{~mL}$ of cinnamon oil and $0.1 \mathrm{~mL}$ of Tween-80 \\
$60: 40$ & $0.12 \mathrm{~mL}$ of cinnamon oil and $0.08 \mathrm{~mL}$ of Tween-80 \\
$70: 30$ & $0.14 \mathrm{~mL}$ of cinnamon oil and $0.06 \mathrm{~mL}$ of Tween-80 \\
\hline
\end{tabular}


The cytotoxicity assay was carried out using 3(4,5-dimethylthiazol-2-yl)-2,5-Diphenyltetrazolium bromide (MTT). The MTT solution was prepared in RPMI-1640 complete medium. The cells that have been seeded were treated with different volume ratios of cinnamon oil and Tween-80 (50:50, 60:40 and 70:30) mixed with the edible Aloe vera mixture. After 24 hours, the test solutions were removed and discarded from the 96-wells plates before adding $50 \mu \mathrm{L}$ of MTT solution into each well on the plates. The plates were then incubated at $5 \% \mathrm{CO}_{2}, 37^{\circ} \mathrm{C}$ for 1 hour and 30 minutes. Next, the media consist of the MTT solution was discarded before $100 \mu \mathrm{L}$ of DMSO was added into each well to dissolve the formazan crystals. Then, the absorbance of each well was measured and recorded at $560 \mathrm{~nm}$ by using a VERSA max microplate reader (Dwivedi et al., 2015; Mazumder et al., 2016). The percentage of cell viability was calculated using the following equation:

$\%$ Cell viability $=\frac{\text { absorbance of treated cells }}{\text { absorbance of untreated cells }} \times 100$

A series of studies were done to determine the most suitable volume ratio of edible Aloe vera matrix incorporated with cinnamon oil that will be safe to be consumed. This was done by evaluating the cytotoxicity effects of the edible matrix towards the normal human lung fibroblast (MRC-5) cell line. MRC-5 is a normal lung fibroblast cells that derived from 14 weeks old Caucasian boy. According to Ballantyne (2006), lung fibroblast cells have been used as a model to evaluate the cytotoxicity effect of test materials for safety. The cytotoxicity results are represented as the means percentage of cell viability shown in Figure 1. Moreover, all of the different concentration ratios of cinnamon oil and Tween- 80 are affecting cell viability differently in a time-dependent manner. At 24 hours, edible Aloe vera matrix showed no significant difference on MRC-5 cell viability after treated with three different concentration ratios (50:50, 60:40, 70:30) of cinnamon oil and Tween- 80 . However, at 48 hours, the cinnamon oil-infused Aloe vera matrix at a concentration ratio of 50:50 and 60:40 caused a significant decreased $(p<0.05)$, on the percentage of MRC-5 cell viability compared to control. Whereas, the cinnamon oil-infused Aloe vera, at a concentration of 50:50 caused a significant reduction in MRC-5 cell viability after 72 hours incubation. Despite its cytotoxicity activity, the percentage of cell death of treated MRC-5 cells with cinnamon oil-infused Aloe vera did not exceed 50\% of inhibition. This result has shown that the formulated natural edible coating is considered to be safe and less cytotoxic to human cells.
According to Rahman et al. (2017), polymer extracts of Aloe vera have high potential as biomaterials in tissue engineering because of variety of benefits, including biodegradability, oxygen permeability, antioxidant action, cell regeneration as well as low toxicity effects. Meanwhile, another research group that was examining the isolated glycoprotein from Aloe vera gel had found that the glycoproteins in the Aloe vera contribute to an antiallergic activity (Choi \& Chung, 2003). The glycoprotein can reduce histamine release and encourage the secretion of leukotrienes in activated lung mast cells (Choi \& Chung, 2003). Thus, this may support the idea that the consumption of edible Aloe vera matrix might contribute to the enhancement of human own body biological reactions such as cell proliferation due to the natural constituents within the Aloe vera (Choi \& Chung, 2003).

(a)

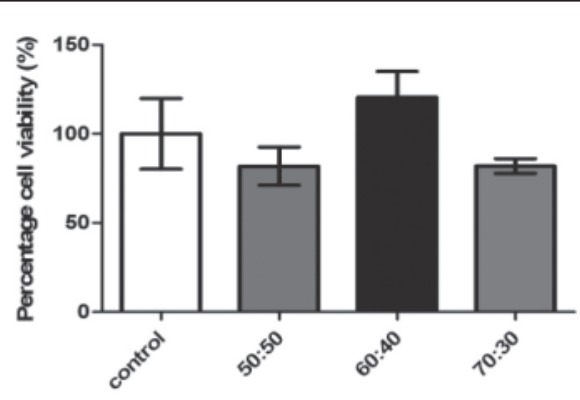

(b)

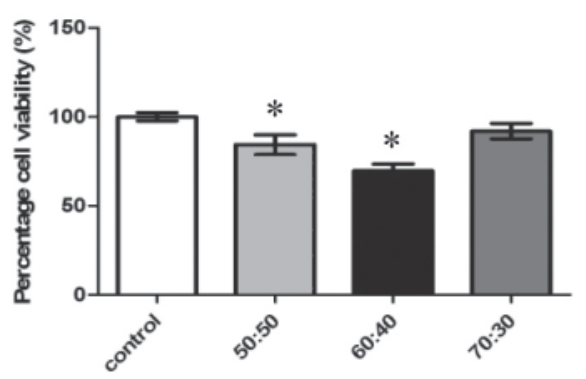

(c)

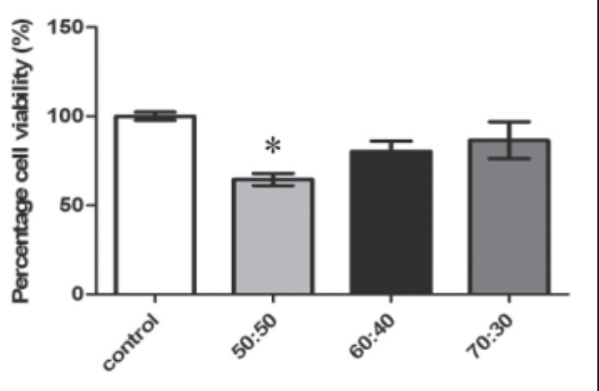

Fig. 1. Determination of percentage of cell viability of MRC-5 cells relative to the mean of the control group after a) 24, b) 48, and c) 72 hours. Data expressed as mean \pm standard error mean. Bars represent standard error mean $\left({ }^{*} p<0.05\right)$. Statistical analysis of t-test, comparing treatment to control $(\mathrm{N}=4)$. 
Barbaloins and other polyphenolic compounds in Aloe vera are useful antioxidants that could scavenge free radicals which may mediate cytotoxicity and lipid peroxidation activities (Cook, 1996). Aloe vera also can comprehend and accommodate in a biological process such as wound healing. According to Rahman et al. (2017), Aloe vera gel is a well-known natural healing agent by activating and enhances cells to proliferate during wound healing. A study by Fox et al. (2017) found that most parts of Aloe species exerted minimal toxicity towards normal human epidermis skin (HaCaT) cells. This statement supports our findings that the formulated edible coatings were less toxic to MRC-5 cells. Meanwhile, Hashemi et al. (2015) stated that a water-soluble polysaccharide in Aloe vera, known as glucomannan, may affect the fibroblast growth factor and triggers cell proliferation which might later enhance collagen production and secretion. In addition, according to Chen et al. (2010), Aloe vera-based as the edible coating may be able to prolong the shelf life of various type of fruits and vegetables, as well as having a great potential in enhancing consumers health.

Besides Aloe vera, cinnamon oil also plays an important role to support the functionality of edible films. The use of cinnamon in a wide range of food can enhance human health due to its antifungal, antibacterial and anticancer properties (RibeiroSantos et al., 2017). A clinical study by Yun et al. (2018) has proven that long-term consumption of cinnamon extracts did not cause any toxicological effects in human. However, further study needs to be done to assess the mechanism involved in the reaction of the mixture between cinnamon oil and edible Aloe vera based towards normal human lung fibroblast MRC-5 cell lines.

To conclude, it is suggested that the most suitable volume ratio of edible Aloe vera film that is safe to be consumed is Aloe vera with a 70:30 ratio of cinnamon oil and Tween- 80 . This is because the edible Aloe vera matrix at this ratio showed a non-cytotoxic effect at 24 hours on normal human lung fibroblast MRC-5 cells. Hence, it is recommended as a safe dosage to be consumed by humans. However, further studies needed to investigate cellular mechanisms of the mixtures in the natural edible coating formulations on various types of human cells, as well as in vivo studies such as rats, rabbits and $C$. elegans to ensure that the products are safe to be consumed.

\section{ACKNOWLEDGEMENT}

The authors would like to thank the Fundamental Research Grant Scheme (FRGS 59484).

\section{REFERENCES}

Atares, L. \& Chiralt, A. 2016. Essential oils as additives in biodegradable fils and coatings for active food packaging. Trends in Food Science \& Technology, 48: 51-62.

Ballantyne, B. 2006. Local and systemic ophtalmic pharmacology and toxicology of organophosphate and carbamate anticholinesterases. In: Toxicology Organophosphate \& Carbamate Compound. R.C. Gupta (Ed.). Academic Press. pp. 423-445.

Chassaing, B., Koren, O., Goodrich, J.K., Poole, A.C., Srinivasan, S., Ley, R.E. \& Gewirtz, A.T. 2015. Dietary emulsifiers impact the mouse gut microbiota promoting colitis and metabolic syndrome. Nature, 519(7541): 92-6.

Choi, S. \& Chung, M. 2003. A review on the relationship between aloe vera components and their biological effects. Seminars in Integrative Medicine, 1: 53-62.

Cook, N. 1996. Flavonoids-chemistry, metabolism, cardioprotective effects, and dietary sources. Journal of Nutritional Biochemistry, 7: 66.

Dwivedi, V., Tiwary, S. \& Lakhotia, S.C. 2015. Suppression of induced but not developmental apoptosis in Drosophila by Ayurvedic Amalaki Rasayana and Rasa-Sindoor. Journal of Bioscience, Bangalore, 40(2): 281-297.

Fox, L.T., Mazumder, A., Dwivedi, A., Gerber, M., Plessis, J. \& Hamman, J.H. 2017. In vitro wound healing and cytotoxic activity of the gel and whole-leaf materials from selected aloe species. Journal of Ethnopharmacology, 200: 1-7.

Grigoryev, Y. 2014. Cell counting with a hemocytometer: easy as 1, 2, 3 [WWW Document] URL https://bitesizebio.com/13687/cellcounting-with-a-hemocytometer-easy-as-1-2-3/ (accessed 06.06.19).

Hashemi, S.A., Madani, S.A. \& Abediankenari, S. 2015. The review on properties of Aloe Vera in healing of cutaneous wounds. BioMed Research International, 2015: 1-6.

Joseph, B. \& Raj, S.J. 2010. Pharmacognostic and phytochemical properties of Aloe Vera Linn an overview. International Journal of Pharmaceutical Sciences Review and Research, 4(2): 106-110.

Mazumder, A., Dwivedi, A., Du Preez, J.L. \& Du Plessis, J. 2016. In vitro wound healing and cytotoxic effects of sinigrin-phytosome complex. International Journal of Pharmaceutics, 498(1-2): 283-293.

Noshirvani, N., Ghanbarzadeh, B., Gardrat, C., Rezaei, M.R., Hashemi, M., Coz, C.L. \& Coma, V. 2017. Cinnamon and ginger essential oils to improve antifungal, physical and mechanical 
properties of chitosan-carboxymethyl cellulose films. Food Hydrocolloid, 70: 36-45.

Park, H.J. 1999. Development of advanced edible coatings for fruits. Trends of Food Science and Technology, 10: 254-260.

Pavlath, A.E. \& Orts, W. 2009. Edible films and coatings: why, what, and how? In: Edible Films and Coatings for Food Applications. M.E. Embuscado \& K.C. Huber (Eds.). Springer Science and Business Media, New York. pp. $1-23$.

Rahman, S., Carter, P. \& Bhattarai, N. 2017. Aloe vera for tissue engineering application. Journal of Functional Biomaterials, 8: 6.

Razifah, M.R., Keisheni, G. \& Aidilla, M. 2017. Preparation and characterization of edible Aloe vera films incorporated with cinnamon oil for fruits and vegetables. Malaysian Applied Biology Journal, 46(4): 183-190.
Ribeiro-Santos, R., Motta, J.F.G., Teodoro, C.E.S. \& Melo, N.R. 2017. Antimicrobial effectiveness and color stanbility of protein basedd films incorporated with essential oils. International Food Research Journal, 24(5): 2201-2206.

Verma, R., Vinoda, K.S., Papireddy, M. \& Gowda, A.N.S. 2016. Toxic pollutants from plastic waste - a review. Procedia Environmental Sciences, 35: 701-708.

Yun, J.W., You, J.R., Kim, Y.S., Kim, S.H., Cho, E.Y., Yoon, J.H., Kwon, E., Jang, J.J., Park, J.S., Kim, H.C., Che, J.H. \& Kang, B.C. 2018. In vitro and in vivo safety studies of cinnamon extract (Cinnamomum cassia) on general and genetic toxicology. Regulatory Toxicology and Pharmacology, 95: 115-123. 
